\title{
Computed tomography in chronic inflammatory bowel disease
}

\author{
W Hyer, R M Beattie, J A Walker-Smith, A McLean
}

\begin{abstract}
In children with complicated inflammatory bowel disease, conventional ultrasound imaging may not define the extent of extraluminal disease and the involvement of other viscera. Three children with chronic inflammatory bowel disease are presented, where computed tomography was well tolerated and provided valuable information on extraluminal disease, involvement of other organs, and the state of the bowel wall and mesentery. In children in whom ultrasound examination is inconclusive or limited by gas or tenderness, computed tomography can provide important information that may determine clinical management.

(Arch Dis Child 1997;76:428-431)
\end{abstract}

Keywords: Crohn's disease; computed tomography

Initial diagnosis of inflammatory bowel disease in children requires a combination of barium studies, endoscopy, and biopsy to define the extent of disease. ${ }^{1}$ In severe ulceration, transmural disease may result in mesenteric changes and extraintestinal complications which cannot be defined by barium studies. Cross sectional imaging is required to define the extent of extraluminal disease to determine management. In the paediatric patient, ultrasound is the first line investigation, but not infrequently fails to define the extent of the clinical problem fully. In these circumstances, computed tomography has been shown in adult patients to influence management ${ }^{2-5}$; however, there are only limited reports of its use in paediatric practice. We present three children with inflammatory bowel disease in whom computed tomography contributed valuable information and influenced clinical management.

\section{Case reports}

CASE 1

A 16 year old boy was admitted with an acute history of abdominal pain, fever, and anorexia. He had a nine year history of ileocaecal Crohn's disease and had been treated with a right hemicolectomy at the age of 12 years. $\mathrm{He}$ subsequently developed an anastomotic relapse which required further small bowel resection. Before this episode, he had been in remission for two years.

On admission he was tachycardic and dehydrated. Investigations showed a haemoglobin of $88 \mathrm{~g} / 1$, white blood count (WBC) $24 \times 10^{9} / 1$, platelets $638 \times 10^{9} / 1$, erythrocyte sedimentation rate (ESR) $69 \mathrm{~mm} / \mathrm{h}$, albumin $29 \mathrm{~g} / \mathrm{l}$, and C reactive protein $115 \mathrm{mg} / \mathrm{l}$. Plain abdominal $x$ ray showed moderate proximal constipation, but no small bowel dilatation. Ultrasound examination revealed a thick walled rectum but no evidence of a fluid collection. Sigmoidoscopy under anaesthesia showed moderate rectal inflammation. $\mathrm{He}$ was treated with intravenous antibiotics, corticosteroids, and total parenteral nutrition. Despite this, he remained very unwell and developed a swinging pyrexia to $39^{\circ} \mathrm{C}$.

Because of concern about the presence of an occult abscess, computed tomography was performed to assess the rectum and perineum further. This showed gross thickening of the sigmoid colon and rectal wall with complete loss of the perirectal fat planes, and adherence of the rectum to the bladder. Despite the extensive inflammatory change no discrete pelvic collection was seen (fig $1 \mathrm{~A}$ and $\mathrm{B}$ ). A diversion colostomy was performed to defunction the area of diseased bowel, with the rectum left
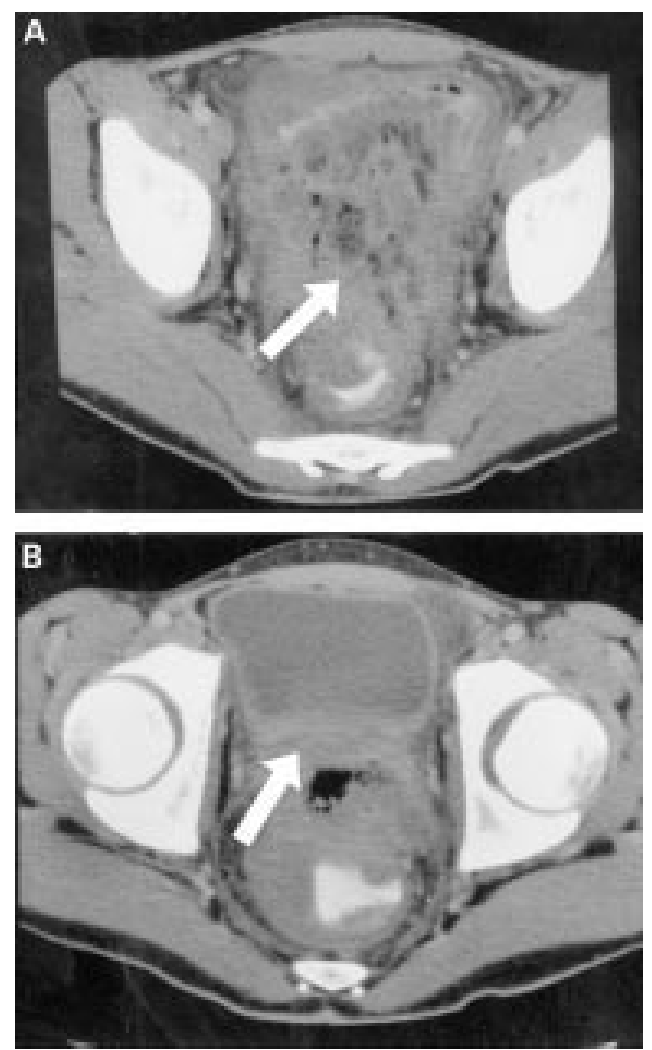

Figure 1 Case 1. Computed tomography of pelvis with rectal contrast, showing $(A)$ marked inflammation of perirectal tissue with loops of small bowel and sigmoid colon adhering to the rectum (arrow), and (B) gross asymmetrical thickening of the rectal wall and posterior wall of the bladder (arrow). 

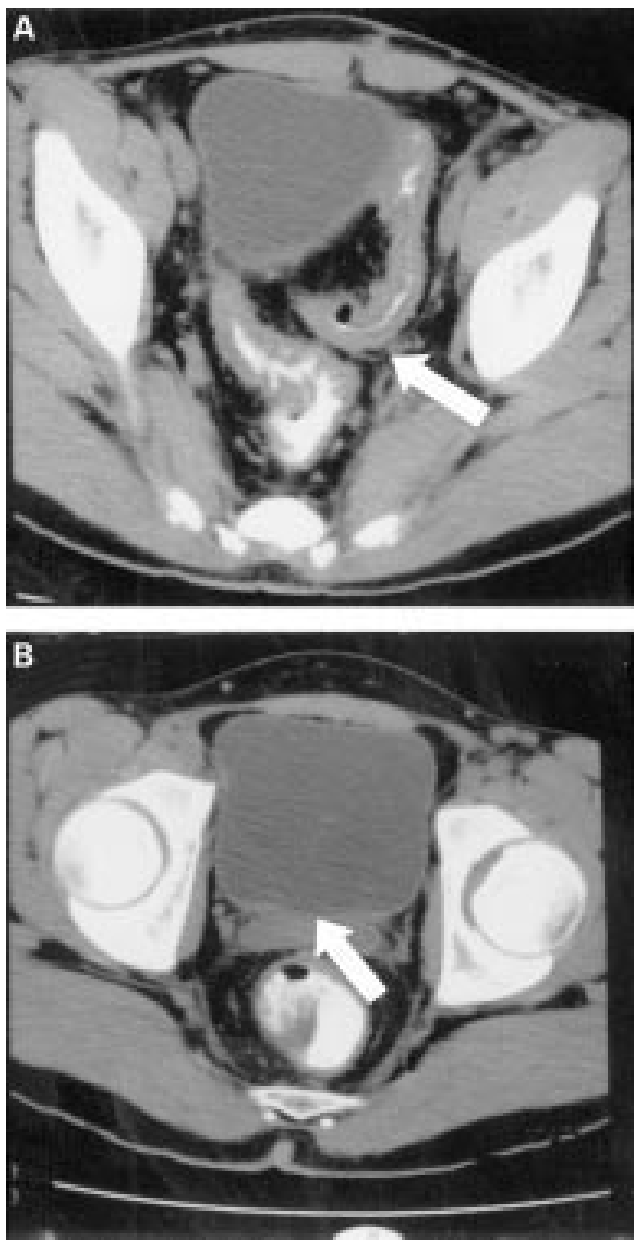

Figure 2 Case 1. Computed tomography with rectal contrast after diversion colostomy at the same level as fig 1. Compared with fig 1, note $(A)$ the marked improvement in pelvic inflammation (arrow) and (B) the reduction in rectal and vesical wall thickening (arrow).

in situ. The postoperative period was complicated by a rectovesical fistula which settled spontaneously.

Two months after surgery, repeat computed tomography showed dramatic improvement, with restoration of the pelvic fat planes, reduction in bowel wall thickening, and no evidence of rectovesical fistula (fig $2 \mathrm{~A}$ and $\mathrm{B}$ ). $\mathrm{He}$ remains in remission.

CASE 2

An 11 year old girl presented with a two month history of bloody diarrhoea, lower abdominal pain, recurrent mouth ulceration, and a $6 \mathrm{~kg}$ weight loss. On examination she was afebrile with a soft but tender abdomen. Investigations showed haemoglobin $85 \mathrm{~g} / \mathrm{l}$, WBC $9.0 \times 10^{9} / 1$, platelets $520 \times 10^{9} / 1$, ESR $36 \mathrm{~mm} / \mathrm{h}$, and C reactive protein $41 \mathrm{mg} / \mathrm{l}$. The presumptive diagnosis was inflammatory bowel disease with active colitis, which was confirmed at colonoscopy. She was transfused and started on intravenous hydrocortisone, antibiotics, and fluids with initial improvement. However, after four days of treatment, she deteriorated with increasing pain, diarrhoea, fever, and abdominal tenderness. An emergency subtotal colectomy was performed with the formation of a
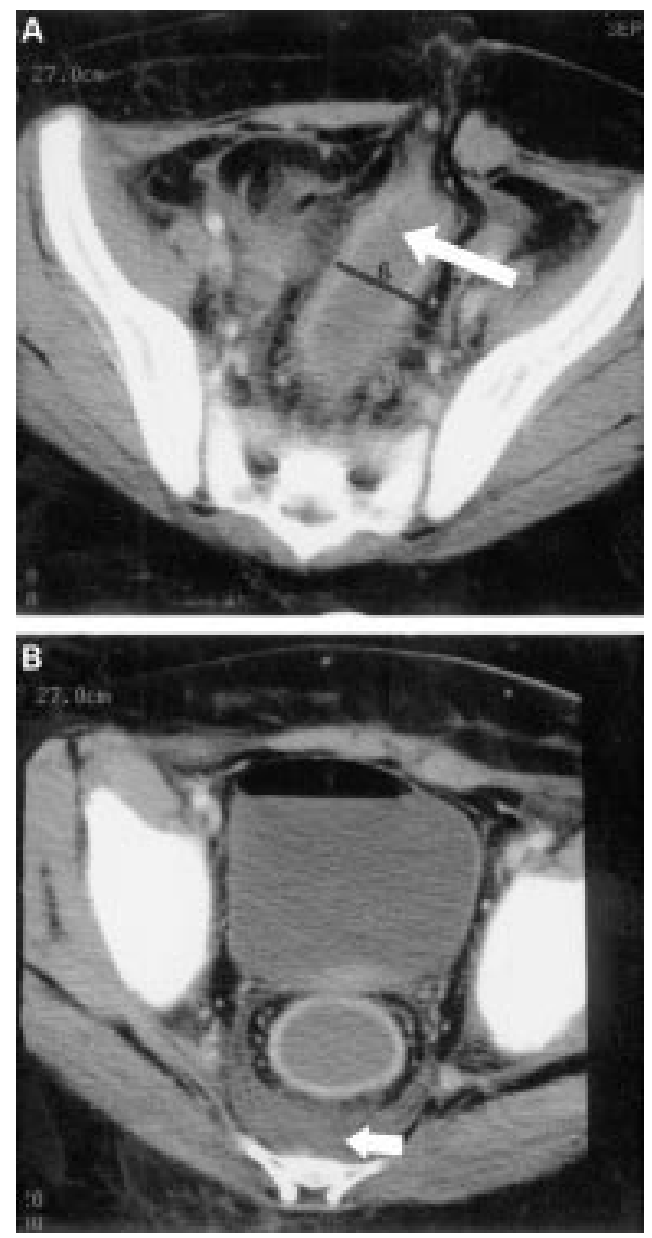

Figure 3 Case 2. Computed tomography of pelvis showing (A) a severely inflamed, thick walled, defunctioned rectum distended with fluid (arrow) leading to the mucous fistula on the anterior abdominal wall. (B) There is marked thickening of the presacral soft tissues (arrow).

mucous fistula and ileostomy. Histology confirmed fulminant ulcerative colitis. Her initial postoperative course was unremarkable, but on the fifth postoperative day she collapsed with dehiscence of the mucous fistula into the peritoneal cavity, resulting in peritonitis. This was corrected surgically but she remained unwell and a pelvic abscess was suspected. Ultrasound showed a fluid collection behind the bladder but could not clearly identify the defunctioned rectum. Computed tomography showed the fluid collection to be the severely inflamed, thick walled rectum distended with fluid. There was an inflammatory mass in the presacral space, with lymphadenopathy along the line of the retained colon (fig 3A and B).

Surgical removal of the rectum was considered but a conservative approach was adopted, with rectally administered steroid enemas and drainage of the rectal fluid. Her condition improved but over the next three weeks she continued to have recurrent fevers and developed deep perianal and sacral ulcers and her inflammatory indices remained persistently high $(\mathrm{C}$ reactive protein $110 \mathrm{mg} / \mathrm{l})$. Computed tomography was repeated and showed improvement in the rectal wall with reduced presacral swelling, but there were multiple peri- 

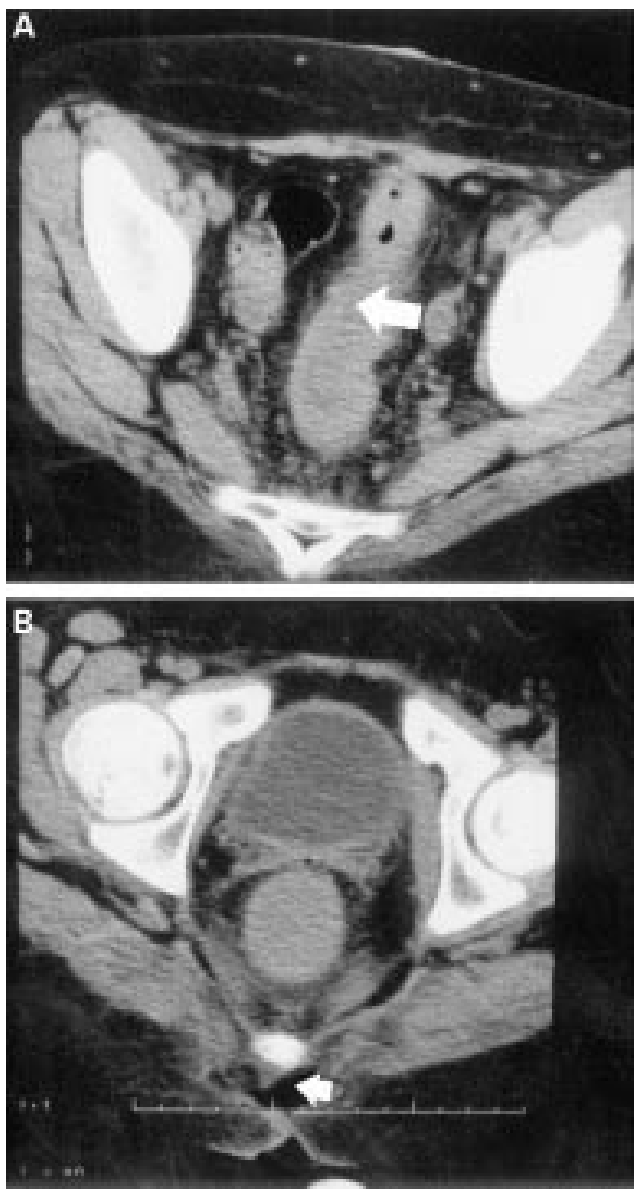

Figure 4 Case 2. Computed tomography of pelvis after treatment $(A)$. Compared to fig $3 A$, there is a reduction in the distension of the rectum (arrow). In (B) improvement in rectal wall thickening can be seen but tracts are visible extending from the soft tissues into the posterior coccygeal regions (arrow) adjacent to the radio-opaque spine.

anal sinus tracts extending from the presacral space into the gluteal muscles together with dehiscence of the abdominal wound around the fistula. No discrete abscess was identified (fig $4 \mathrm{~A}$ and $\mathrm{B}$ ).

With the information provided by the computed tomography, conservative management was pursued with increased nutritional supplementation and a reduction in oral steroids. She was discharged 42 days after surgery on prednisolone enemas. Currently at six months' follow up she is well.

CASE 3

A 3.5 year old girl with Crohn's colitis diagnosed at age 2 years presented in relapse with severe perianal pain, bloody diarrhoea, and recurrent fever. Investigations showed haemoglobin $82 \mathrm{~g} / \mathrm{l}$, WBC $7.8 \times 10^{9} / 1$, platelets 537 $\times 10^{9} / 1$, ESR $67 \mathrm{~mm} / \mathrm{h}$, and C reactive protein $100 \mathrm{mg} / \mathrm{l}$. Examination under anaesthesia showed erythema of the labia and an apparent fistula opening into the left labium. Abdominal $x$ ray showed an abnormal colonic gas pattern consistent with severe colitis. Ultrasound revealed thickened loops of bowel deep in the pelvis but an abscess could not confidently be excluded. The extent of the perianal disease was such that a contrast study or colonoscopy
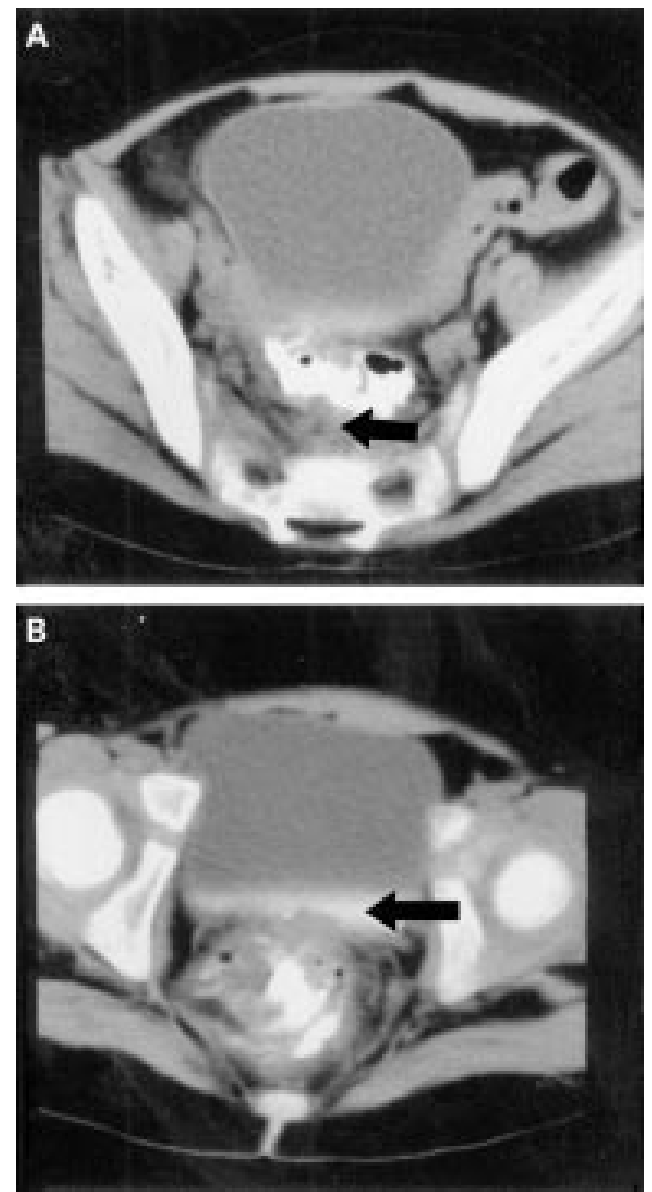

Figure 5 Case 3. Computed tomography of the pelvis, with rectal contrast. (A) Dilatation of the rectum and gross thickening of the rectal wall (arrow). (B) Contrast in the posterior aspect of the bladder (arrow)

could not be tolerated. Computed tomography was therefore performed to assess her perianal disease further and to exclude a fluid collection. This showed mucosal irregularity of the rectal wall extending into the rectosigmoid, with perirectal sinus tracts and a fistulous connection into the vagina. No abscess was seen.

She was started on enteral nutrition with oral prednisolone and azathioprine, but remained unwell with persistent fevers, abdominal pain, diarrhoea, and raised $\mathrm{C}$ reactive protein. Stool was frequently seen at the introitus.

Supine abdominal $x$ ray confirmed mucosal irregularity in the descending colon but there was no evidence of toxic colitis. A limited barium enema under sedation revealed a distended distal colon and rectum, with thickened irregular walls. Ultrasound identified a pelvic mass but it was not possible to determine whether this represented a pelvic collection or distended bowel with thickened wall. Computed tomography was repeated and confirmed markedly thickened sigmoid colon and rectum, with dilatation consistent with colonic Crohn's disease. In addition, the rectovaginal fistula and a probable rectovesical fistula were demonstrated, neither of which had been visualised by other imaging methods (fig $5 \mathrm{~A}$ and $\mathrm{B}$ ).

With this information provided by the computed tomography scan, medical treatment was continued and triple antibiotic therapy 
Table 1 Relative merits of imaging methods in paediatric inflammatory bowel disease

\begin{tabular}{|c|c|c|}
\hline Barium studies & Ultrasound & Computed tomography \\
\hline \multirow{2}{*}{$\begin{array}{l}\text { Identifying early disease, } \\
\text { mucosal oedema and } \\
\text { ulceration, enteroenteric } \\
\text { fistulae, and longitudinal } \\
\text { extent of disease }\end{array}$} & $\begin{array}{l}\text { First investigation in } \\
\text { complicated disease }\end{array}$ & If ultrasound diagnosis is unclear \\
\hline & $\begin{array}{l}\text { Identifying bowel wall } \\
\text { changes, mesenteric } \\
\text { inflammation and } \\
\text { abscess }\end{array}$ & $\begin{array}{l}\text { Identifying bowel wall strictures, } \\
\text { mesenteric inflammation, } \\
\text { abscesses and fistulae-- } \\
\text { enterocutaneous, enterovesical, } \\
\text { or retroperitoneal }\end{array}$ \\
\hline \multirow{6}{*}{$\begin{array}{l}\text { Evaluation of postoperative } \\
\text { anatomy, stricture or } \\
\text { obstruction }\end{array}$} & & \\
\hline & Limitations & With spiral computed tomography \\
\hline & Postoperative & Quick \\
\hline & Tenderness & Well tolerated \\
\hline & Gas & 2-D reconstruction \\
\hline & $\begin{array}{l}\text { Deep pelvic collections } \\
\text { Demonstration of } \\
\text { fistulae }\end{array}$ & Evaluate small bowel obstruction \\
\hline Radiation dose $6.0-9.0 \mathrm{mSV}$ & Radiation dose: none & Radiation dose $8.0 \mathrm{mSV}$ \\
\hline
\end{tabular}

(cefotaxime, gentamicin, and metronidazole) added. In view of her severe perianal and rectal disease a defunctioning loop ileostomy was fashioned. Following this, her condition rapidly improved, inflammatory indices improved, and a normal diet was introduced. She remains well at six months' follow up.

\section{Discussion}

Barium studies and colonoscopy remain the initial first line diagnostic investigation of a patient with suspected Crohn's disease. The ability of ultrasound to visualise the bowel wall and its surrounding mesentery is now a valuable diagnostic tool which may have a role in the initial diagnosis of Crohn's disease and can be used to evaluate the attendant complications. Ultrasound is readily available, flexible, cheap, and has the advantage of not exposing the paediatric patient to ionising radiation. ${ }^{6}$ However, in some patients it is difficult to define the full extent of disease with ultrasound, particularly in those patients with abdominal wall tenderness, or in the postoperative period. It can be difficult to exclude confidently the presence of an abscess at ultrasound, and sinus tracts may be difficult to follow. Magnetic resonance imagine (MRI) may specifically look at perianal disease but has limited use in other areas in patients with inflammatory bowel disease. ${ }^{7}$ There is limited availability and experience of this technique, and there is no suitable bowel contrast. Many patients find an MRI scan an unpleasant experience.

Computed tomography, especially where spiral scanning is available, provides a rapid, painless, and highly informative investigation which can be accomplished within a few minutes at no discomfort to the patient. With spiral scanning, data can be reconstructed in other planes to provide further useful information.

In the three cases illustrated, computed tomography yielded information regarding the condition of the rectum, identifying intraabdominal collections, extramural disease, involvement of other organs, and enterovesical and enterocutaneous fistulae. Deep pelvic structures are easily visualised and the ability to obtain good images is not limited by bowel gas or abdominal wall tenderness. This mode of imaging provided information which was not available on ultrasound scans and subsequently determined surgical or medical management.

The use of computed tomography in inflammatory bowel disease is well documented. In one study it led to a change in patient management in 22 of 80 adult patients with Crohn's disease, and identified unsuspected findings in 13 patients. $^{5}$ There are reports of computed tomography in paediatric patients with inflammatory bowel disease, ${ }^{8-11}$ although its use is less well established.

The radiation involved in computed tomography limits its use as a first line investigation. However, the radiation from current scanners from a pelvic examination $(8.0 \mathrm{mSV})$ is the equivalent of a barium follow through or a barium enema and may yield more information in the sick paediatric patient with complicated inflammatory bowel disease (table 1). In our experience computed tomography is of great value if ultrasound fails to resolve the clinical problem.

RMB is supported by the Crohn's in Childhood Research Association (CICRA).

1 Walker-Smith JA. Clinical and diagnostic features of Crohn's disease and ulcerative colitis in childhood. Baillieres Clin Gastroenterol 1994;8:65-81.

2 Gore RM, Marn CS, Kirby DF, Vogelzang RL, Neiman HL. CT findings in ulcerative, granulomatous and indeterminate colitis. Am $\mathcal{F}$ Radiol 1984;143:279-84.

3 Jones B, Fishman EK, Siegelman SS. Ischaemic colitis demJones B, Fishman EK, Siegelman SS. Ischaemic colitis dem-
onstrated by computed tomography. F Comput Axial Tomogr

4 Philpotts LE, Heiken JP, Westcott MA, Gore RM. Colitis: use of CT findings in differential diagnosis. Radiology use of CT finding

5 Fishman EK, Wolf EJ, Jones B, Bayless TM, Siegelman SS. CT evaluation of Crohn's disease: effect on patient management. Am F Radiol 1987;148:537-40.

6 Sheridan MB, Nicholson DA, Martin DF. Transabdominal ultrasonography as the primary investigation in patients with suspected Crohn's disease or recurrence: a prospective study. Clin Radiol 1993;48:402-4

7 Myhr GE, Myrvold HE, Nilsen G, Thoreson JE, Rinck PA. Perianal fistulas: use of $\mathrm{MR}$ imaging for diagnosis. Radiology 1994;191:545-9.

8 Jabra AA, Fishman EK, Taylor GA. CT findings in inflammatory bowel disease in children. Am $\mathcal{F}$ Radiol 1994;162: 975-9.

9 Siegal MJ, Evans SE, Balfe DM. Small bowel disease in children: diagnosis with CT. Radiology 1988;169:127-30.

10 Riddlesberger MM. CT of complicated inflammatory bowel disease in children. Pediatr Radiol 1985;5:384-7.

11 Jabra AA, Fishman EK, Taylor GA. Crohn's disease in the pediatric patient: CT evaluation. Radiology 1991;179:495-8. 